\title{
Aggression predicts Cortisol Awakening Response in healthy young adults
}

\author{
Patricia Sariñana-González, Ángel Romero-Martínez and Luis Moya-Albiol*
}

Department of Psychobiology. Faculty of Psychology. University of V alencia. (Spain).

\begin{abstract}
Título: La Agresión como variable predictora de la Respuesta Matutina de Cortisol en adultos jóvenes.

Resumen: Parece que el cortisol (C) se relacionaría de forma inversa con el comportamiento agresivo, pero esta relación ha sido más claramente establecida con el cortisol vespertino. Sin embargo, la relación con la respuesta matutina de cortisol (CAR) y la influencia del género y la fase del ciclo no estaría tan clara. Este estudio analiza dicha relación en 83 mujeres (38 en fase lútea y 45 en fase folicular del ciclo menstrual) y 20 hombres. La CAR se obtuvo a partir de muestras de saliva recogidas inmediatamente y después del despertar (a los 30, 45 y 60 minutos después). Además, los participantes cumplimentaron un autoinforme de agresión. Los hombres presentan niveles más bajos de CAR que las mujeres en fase lútea y una mayor agresión física que las mujeres, independientemente de la fase del ciclo en la que se encuentren. Respecto a las relaciones entre las variables, en los hombres la agresión en general y la verbal predijeron la CAR en hombres. En mujeres, la agresión verbal predijo la CAR durante la fase folicular, mientras que la ira y la agresión física durante la lútea. Nuestra investigación apoya que existiría una relación negativa entre el $\mathrm{C}$ y las conductas agresivas, incluso con los niveles de $\mathrm{C}$ matutino. Además, la relación entre ambas variables fue moderada por el género y por la fase del ciclo menstrual en el caso de las mujeres. Estos resultados podrían incrementar el conocimiento existente sobre los mecanismos envueltos en la violencia.

Palabras clave: agresión; respuesta matutina de cortisol; género; ciclo menstrual; sano; joven.
\end{abstract}

\section{Introduction}

Aggressive behavior imposes an enormous cost on society and psychobiological mechanisms may be important for explaining individual variations in antisocial behavior (Krug, Mercy, Dahlberg, \& Zwi, 2002). The hypothalamic-pituitaryadrenal (HPA) axis, and especially its end-products (glucocorticoids), are involved in aggressive behavior (MoyaAlbiol, 2010). The primary glucocorticoid in humans is cortisol (C), which can be reliably measured in saliva (Kirschbaum \& Hellhammer, 1994). A useful indicator of the basal activity of the HPA axis is the $\mathrm{C}$ awakening response (CAR). CAR reflects the circadian rhythm and is characterized by a rapid $\mathrm{C}$ secretion after awakening, peaking after 30 to 45 minutes (Clow, Hucklebridge, Stalder, Evans, \& Thorn, 2010). While it varies between individuals, it is characterized by high intra-individual stability (Hellhammer, et al., 2007) and this stability makes it particularly suitable for studies of the relationship between $\mathrm{C}$ and relatively stable psychosocial characteristics (Chida \& Steptoe, 2009).

However, the impact of gender and the menstrual cycle on the CAR is unclear. Neither gender nor menstrual phase were found to significantly affect the pattern of cortisol levels in adolescents measured after awakening and 30 minutes later (Bouma, Riese, Ormel, Verhulst, \& Oldehinkel, 2009).

* Dirección para correspondencia [Correspondence address]:

Dr. Luis Moya Albiol. Departament of Psychobiology. Faculty of Psychology. University of Valencia. Avenida Blasco Ibañez, 21. 46010, Valencia. España (Spain). E-mail: Luis.Moya@uv.es
Abstract. It seems that aggressive behavior is negatively related to cortisol (C), but this relationship has been established considering the evening C levels. On the other hand, the relationship with the $\mathrm{C}$ awakening response $(\mathrm{CAR})$ and the influence of gender and menstrual cycle phase are not well understood. This study analyzed this relationship in 83 women (38 in the luteal and 45 in the follicular phase of their menstrual cycle) and 20 men. CAR was assessed by measuring salivary free cortisol levels in samples taken immediately following awakening and 30, 45, and 60 minutes later. Additionally, participants completed a self-report of aggression. Men presented lower CAR than women in the luteal phase. Moreover, they also had higher levels of physical aggression than women, independently of their menstrual phase. Regarding the relationships between variables, in men general aggression and verbal aggression predicted the CAR. In women, verbal aggression predicted the CAR during the follicular phase, whereas anger and physical aggression were predictors during the luteal phase. Our data support the view that there is a negative relationship between $C$ and aggressive behavior, even during the morning, this relationship being moderated by gender and menstrual cycle phase in the women. These findings may help improve our understanding of the biological mechanisms involved in violence.

Keywords: aggression; cortisol awakening response; gender; menstrual cycle; healthy; young.

Moreover, while one study reported higher CAR in healthy adult women than in men (Kunz-Ebrecht, Kirschbaum, Marmot, \& Steptoe, 2004), another reported a lack of gender differences (Kudielka \& Kirschbaum, 2003). The latter authors also observed no effects of the menstrual cycle on the CAR through the morning (with $\mathrm{C}$ levels measured after awakening and 15, 30, 45 and 60 minutes later), but a more recent study found that the CAR (after awakening, and 30, 45 and 60 minutes later) was stronger during ovulation than during follicular, luteal, and menstruation phases (Wolfram, Bellingrath, \& Kudielka, 2011).

Regarding the effect of $\mathrm{C}$ on aggression, a diametrically opposed relationship between salivary $\mathrm{C}$ and social aggression has frequently been observed in subjects with aggressive or rule-breaking behavior, although the results are far from homogeneous. Indeed, in measurements over the day, to assess CAR and diurnal rhythm (30 and 60 minutes after awakening, before and after lunch, in the afternoon and before going to bed), C levels were significantly lower in delinquent male adolescents than in controls (Popma, et al., 2007). Recently, in a longitudinal study, low C levels have been described at awakening in highly aggressive adolescents (Platje, et al., 2013). Moreover, studies of adult men with violent or antisocial personality disorders have shown a damped response in diurnal salivary samples when measured at 8.00 a.m., 11.00 a.m., 2.00 p.m. and 4.00 p.m. (Cima, Smeets, \& Jelicic, 2008). Similar to the findings in men, low morning basal salivary $C$ levels (in samples collected within the first 30 minutes after awakening) have been associated 
with dangerous violent criminal behavior (including murder) in female prison inmates (Brewer-Smyth, Burgess, \& Shults, 2004). In contrast, $C$ levels have been reported to be higher in boys with than without conduct disorder in samples collected in the morning (van Bokhoven, et al., 2005). Further, evening C levels ( 9 p.m.) were significantly higher in male adolescents with conduct disorder than in controls (Fairchild, et al., 2008).

While several studies have found an association between $C$ levels and antisocial behavior in subjects with behavioral problems, there are fewer data on control groups and nonaggressive populations in general. In healthy non-violent women, a negative relationship was observed between basal CAR levels and aggressive behavior elicited with the Taylor Aggression Paradigm (TAP), which consists of a competitive reaction time game against a fictitious same-sex opponent (Böhnke, Bertsch, Kruk, \& Naumann, 2010a); the trend was also observed in men, but did not reach significance. On the other hand, high CAR levels after the administration of hydrocortisone were associated with high levels of aggressive behavior in the TAP (Böhnke, Bertsch, Kruk, \& Naumann, 2010b). In both these studies, CAR was assessed on 3 consecutive weekdays prior to the experiment. However, to our knowledge, no studies have focused on gender differences controlling for menstrual cycle phase in the relationship between CAR and trait aggression, or different components of aggression, in non-rule-breaking individuals.

The primary objective of this study was to determine whether women in different menstrual cycle phases have different aggression scores to men. As demonstrated previously, men tend to be more physically aggressive than women. On the other hand, women tend to show higher levels of verbal aggression than men (Archer, 2009; Bjtirkqvist, 1994; Buss, \& Perry, 1992; Tsorbatzoudis, Travlos, \& Rodafinos, 2013). Further, it has been reported that women present higher levels of physical aggression in the luteal than the follicular phase (Ritter, 2003). Hence, we expected that men would present higher levels of physical aggression than women in the follicular phase. Further, we hypothesized that women in the luteal phase would present higher levels of verbal aggression than men.

Secondly, this study explored whether CAR levels differed between women in different menstrual cycle phases and men. It has been stated that the effects of gender and menstrual cycle on the CAR are unclear (Bouma, Riese, Ormel, Verhulst, \& Oldehinkel, 2009; Kunz-Ebrecht, Kirschbaum, Marmot, \& Steptoe, 2004; Kudielka \& Kirschbaum, 2003; Wolfram, Bellingrath, \& Kudielka, 2011). Thus, we did not expect to find gender or menstrual cycle phase differences in CAR. Finally, we explored the relationships of aggressive behavior with CAR levels in each gender and - in women - in different menstrual cycle phases. It has been previously found that CAR is negatively associated with aggressive behavior, especially in women (Böhnke, et al., 2010a; 2010b). Nevertheless, to our knowledge, there has been no research into the relationship between aggressive behavior, CAR and menstrual cycle phases in women. In the light of this lack of data, we hypothesized that aggression would be negatively related to CAR for all the groups.

\section{Method}

\section{Participants}

The initial sample consisted of a total of 200 university students from the University of Valencia. In the preliminary session, all were given a general questionnaire about habits and various aspects of their health. We selected young adults who did not smoke; did not take regular medications or have addictive habits (coffee, tea, drugs); did not have chronic, endocrine and/or cardiovascular diseases; and (in the case of women) had a regular menstrual cycle phase without using oral contraceptives. The final sample was composed of 103 young adult subjects: 20 men, 45 women in the follicular phase, and 38 women in the luteal phase of the menstrual cycle phase. Menstrual cycle phase was calculated on the basis of the first day of the last menses and the cycle length. Only women with a regular cycle between 21 and 35 days over the previous 3 months were included in the analyses concerning menstrual cycle phase (Bouma, et al., 2009). We defined the follicular phase as the period between the first day of the cycle and 14 days before the end of the cycle, while the luteal phase was defined as the last 14 days of the cycle. There were no women in the periovulatory period of the menstrual cycle phase. All the women completed questions about the regularity of their menstrual cycle phase, provided information on the first day of their last menstruation and counted forward to the date they filled out the questionnaire, these questions being answered the same day as the saliva collection. While this forward-cycle method for assessing women's menstrual status has some drawbacks, it is relatively widely used in studies based on surveys (Vermeersch, T'Sjoen, Kaufman, \& Vincke, 2008).

\section{Procedure}

Firstly, participants were instructed to complete an aggression questionnaire, the Buss-Durkee Hostility Inventory (BDHI; see below), and two questions about sleep habits (the number of hours they had slept the previous night and sleep quality, on a scale score of 0 to 100) (see Table 1). They were then instructed how to collect saliva samples at home. These samples, together with their answers to some questions about the saliva collection, were returned to the laboratory within a week.

All subjects participated voluntarily in the study and completed an informed consent form, in accordance with the ethical standards of human research. 
Table 1. Mean (M) and standard deviation (SD) in descriptive characteristics for age, body mass index (BMI), hours of sleep and quality of sleep, for men and women (depending on the menstrual cycle phase).

\begin{tabular}{lccc} 
& Men $(\mathrm{n}=20)$ & Follicular Phase $(\mathrm{n}=45)$ & Luteal Phase $(\mathrm{n}=38)$ \\
$M \pm S D$ & $M \pm S D$ & $20.32 \pm 1.04$ \\
\hline Age (years) & $20.90 \pm 1.62$ & $20.53 \pm 1.14$ & $23.44 \pm 3.68$ \\
BMI $\left(\mathrm{kg} / \mathrm{m}^{2}\right)$ & $25.00 \pm 3.37$ & $22.95 \pm 2.83$ & $7.47 \pm 1.23$ \\
Hours of sleep & $7.39 \pm 1.69$ & $7.84 \pm 1.20$ & $73.33 \pm 14.74$ \\
Quality of sleep & $68.42 \pm 25.51$ & $70.67 \pm 20.49$ & \\
\hline
\end{tabular}

\section{Cortisol awakening response}

Participants were assessed for diurnal cortisol response, using four saliva samples collected with Salivette devices (Sarstedt, Rommersdolf, Germany). Saliva collection is a stress-free approach to assessing $C$ that avoids potential confounding effects produced by venipuncture (Dawes, et al., 1999); and salivary C levels correlate well with free biologically active $\mathrm{C}$ in the blood (Kirschbaum \& Hellhammer, 1994). Participants were given verbal and written instructions about collecting saliva samples immediately after awakening and 30, 45, and 60 minutes later, following previous recommendations (Edwards, Clow, Evans, \& Hucklebridge, 2001; Wüst, Federenko, Hellhammer, \& Kirschbaum, 2000) and were asked avoiding collecting samples at weekends or on any potentially stressful days (Fries, Dettenborn, \& Kirschbaum, 2009). Further, to ensure the quality of the saliva samples, participants were forbidden from drinking (except water), brushing their teeth, eating, or exercising during each sampling period, that is, from waking until they had taken the fourth saliva sample. In addition, participants were asked to store all saliva samples in the fridge until delivering them to the researchers the following day and to take note of the exact time of saliva collection. These instructions were later given again over the telephone the day before saliva collection, in order to encourage observance of the sampling protocol and the timetable for the saliva sampling was also checked.

All saliva samples were collected within a period of two months and frozen at $-20^{\circ} \mathrm{C}$ until analysis by radioimmunoassay using a cortisol Coat-A-Count kit (DPC-Siemens Medical Solutions Diagnostics) with $1.0 \mathrm{nmol} / 1$ sensitivity. All samples were analyzed in duplicate and the samples of the same participant were included in the same assay. Although the limit for the coefficient of variation for replication was set at $8 \%$, the maximum intra- and inter-assay variation coefficients obtained were 4.3 and $5.2 \%$ respectively.

\section{Trait aggressiveness}

Aggression was assessed by means of the Spanish version of the BDHI (Buss \& Durkee, 1957; Buss \& Perry, 1992; Gómez, Rodríguez, \& Fernández, 2002). The questionnaire is composed of 29 items ranked on a five-point Likert scale, and divided into four subscales: physical aggression, verbal aggression, anger and hostility. The total score on this scale is calculated by summing the scores on all the subscales. The Spanish version of the BDHI has shown an in- ternal consistency coefficient for all the subscales of between .68 and .86 , with Cronbach's alpha for the total score being .88 .

\section{Data analysis}

After confirming the normality of the data using the Kolmogorov-Smirnov test $(p<.001)$, the group differences (men, women in follicular phase and women in luteal phase) in anthropometric variables, sleep habits (hours and quality) and aggression scores were analyzed with one-way ANOVAs with Bonferroni post-hoc tests.

For analyzing differences in levels of CAR between the groups at each time point, repeated ANCOVA measures were applied with 'time point' as the within-subject factor (in three levels: 30, 45 and 60 minutes after awakening), and 'group' as the between-subjects factor (men, women in follicular phase and women in luteal phase). The $\mathrm{C}$ level from the first sample was included as a covariate as previous studies indicate that awakening time affects the CAR (Fries et al., 2009; Kudielka \& Kirschbaum, 2003). Greenhouse-Geisser adjustments for degrees of freedom were applied where appropriate.

The magnitude of $\mathrm{C}$ responses was estimated by the area under the curve (AUC) method, considering the AUC with respect to increase $\left(\mathrm{AUC}_{\mathrm{i}}\right)$ and ground $\left(\mathrm{AUC}_{\mathrm{g}}\right)$ (Hellhammer, et al., 2007). Both AUCs were calculated using the trapezoidal rule (Kirschbaum, Kudielka, Gaab, Schommer, \& Hellhammer, 1999; Pruessner, Kirschbaum, Meinlschmid, \& Hellhammer, 2003), taking the initial values from just after awakening as a reference. The equations are basically simple additions of areas consisting of triangles and rectangles. $A U C_{i}$ is calculated with reference to the baseline measurement and it ignores the offset from zero for all measurements and, hence, emphasizes the changes over time. On the other hand, $\mathrm{AUC}_{\mathrm{g}}$ is the total area under the curve of all measurements and assesses the distance of these measures from ground. Regarding hormonal parameters, $\mathrm{AUC}_{\mathrm{i}} \mathrm{em}-$ phasizing changes over time is more related to sensitivity of the system, whereas $\mathrm{AUC}_{\mathrm{g}}$ reflects total hormonal output or levels (Grice \& Jackson, 2004; Romero-Martínez, et al., 2014). For analyzing differences in the magnitude of the CAR ('AUC $\mathrm{i}_{\mathrm{i}}$ or $\mathrm{AUC}_{\mathrm{g}}$ ') in groups, one-way ANOVAs were performed with Bonferroni post-hoc tests. A hierarchical regression model (stepwise method) was also built to determine which factors of aggression were predictors of the $\mathrm{AUC}_{\mathrm{i}}$ and $\mathrm{AUC}_{\mathrm{g}}$ of CAR for each group. 
Data analyses were carried out using IBM SPSS Statistics for Windows, version 19.0 (IBM Armonk, NY). Results were considered statistically significant for $p$ values $\leq .05$ and $\leq .01$, though values less than .07 have been taken to indicate a trend to significance. The descriptive data are expressed as mean and standard deviation ( $\mathrm{M} \pm \mathrm{SD}$, respectively).

\section{Results}

\section{Sample characteristics and cortisol measurements}

No significant differences in CAR were found between groups by age, BMI, hours of sleep, or sleep quality. Nevertheless, a significant effect was found for the physical aggression subscale, $F(2,102)=3.11, p=.049$, men presenting more physical aggression than women in the follicular phase $(p=.07)$. Descriptive data and statistics for each group are shown in Table 2 .

As expected, a statistically significant variation in $\mathrm{C}$ levels was found across all time points for all participants, $F(1.74$, $177.44)=40.38, p=.0001$. Pairwise comparisons showed that the main Time Point effect was attributable to an increase in $\mathrm{C}$ levels between awakening and the other all the other time points at which samples were taken, and a decrease between 30 and 45 minutes after awakening (for all $p$ $=.0001)$. Additionally, data analysis showed a main effect of Group on C levels, $F(2,99)=3.31, p=.041$, specifically at 30 and 45 minutes after awakening ( $p=.0001$, respectively) with men presenting lower levels of $C$ than women in the luteal phase $(p=.035)$. No significant differences in CAR were found between the groups as a function of $\mathrm{AUC}_{\mathrm{i}}$ or $\mathrm{AUC}_{\mathrm{g}}$. Measurements of CAR are presented in Figure 1.

Table 2. Scores of subscales of aggression for participants. Values expressed in $\mathrm{M} \pm \mathrm{SD} .{ }^{*} \mathrm{p}<0.05$

\begin{tabular}{lccc}
\hline & Men $(\mathrm{n}=20)$ & Follicular Phase $(\mathrm{n}=45)$ & Luteal Phase $(\mathrm{n}=38)$ \\
& $M \pm S D$ & $M \pm S D$ & $15.20 \pm 4.95$ \\
Physical aggression* & $16.30 \pm 5.66$ & $13.40 \pm 3.92$ & $11.89 \pm 3.38$ \\
Verbal aggression & $13.30 \pm 3.09$ & $12.16 \pm 3.27$ & $17.37 \pm 4.96$ \\
Anger subscale & $17.25 \pm 5.83$ & $16.00 \pm 5.08$ & 17.39 \\
Hostility & $19.00 \pm 5.39$ & $17.00 \pm 5.11$ & 62.16 \\
Total aggression & $65.85 \pm 9.79$ & $58.55 \pm 12.53$ & 14.13 \\
\hline
\end{tabular}

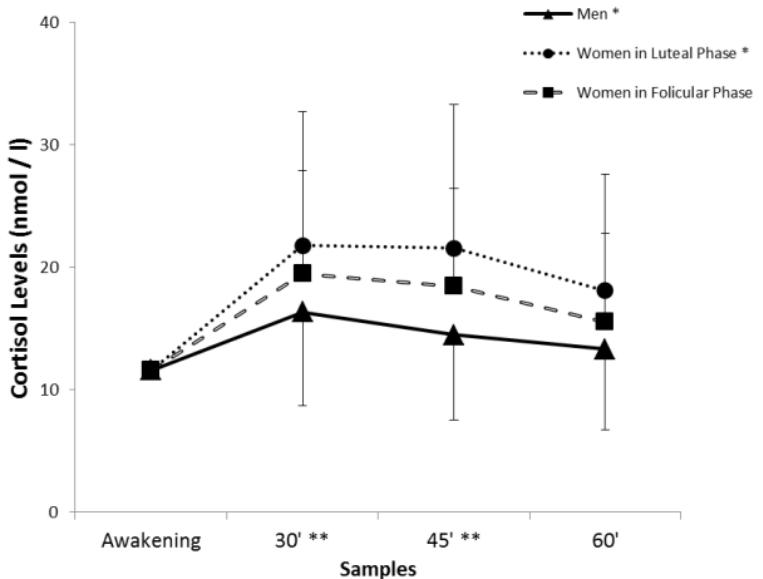

\section{Is aggression a predictor of cortisol awakening re- sponse?}

The effects of aggression on the AUC of CAR were analyzed separately for each group. Regarding men, the final model of $\mathrm{AUC}_{\mathrm{i}}$ of $\mathrm{CAR}$ included verbal aggression as the only significant predictor, $F(1,19)=5.186, \mathrm{p}=.03$, this type of aggression explaining $18.1 \%$ of the variance $(\beta=.473)$ (see Figure 2). On the other hand, for $\mathrm{AUC}_{\mathrm{g}}$ of CAR, the final model included the total aggression score as the only significant predictor, $F(1,19)=7.750, \mathrm{p}=.012$, the total score explaining $30.1 \%$ of the variance $(\beta=.549)$.

Figure 1. C levels (nmol/L) at awakening and at 30, 45 and 60 minutes later for men and women. $\mathrm{C}$ levels expressed in $\mathrm{M} \pm \mathrm{SD} .{ }^{*} p \leq .05,{ }^{* *} p \leq .01$.

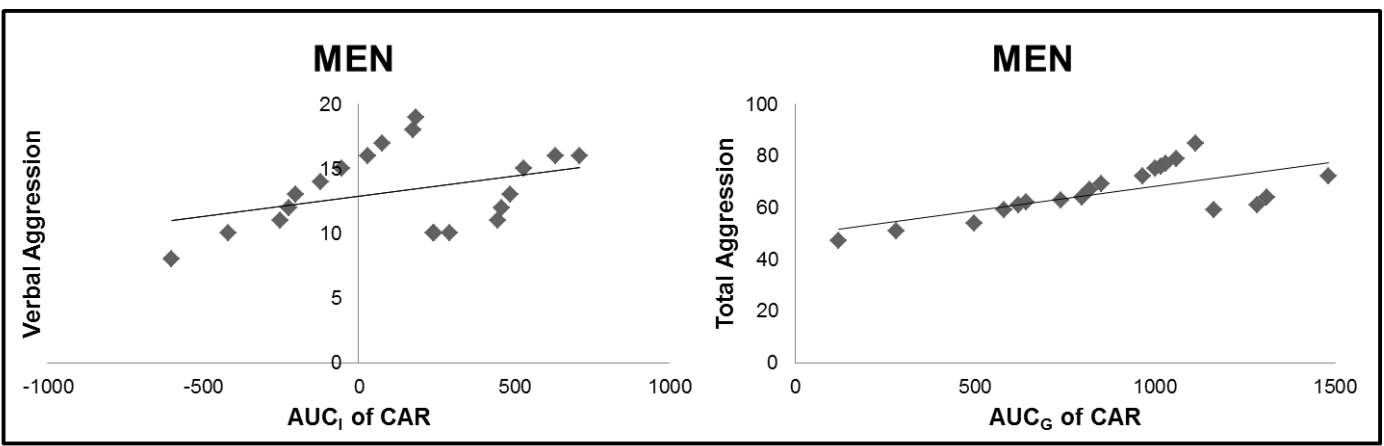

Figure 2. Relationship between AUC of CAR and verbal and total aggression for men, $p \leq .05$. 
Regarding women, overall, an effect of aggression was only found on $A U C_{i}$ of CAR (see Figure 3). In the case of women in the follicular phase, the final model included verbal aggression as a significant predictor, $F(1,44)=4.736$, $p$ $=.035$, this variable explaining $7.8 \%$ of the variance $(\beta$ $=.315$ ), while for women in luteal phase, in the first step, the model included anger as the only significant predictor, $F$ (1, $37)=4.978, p=.032$, and it explained $9.7 \%$ of the variance $(\beta=.349)$. In step 2 , the inclusion of physical aggression, $F$ $(2,37)=6.255, p=.005$, significantly increased the amount of variation explained $\left(\beta=-.407, \mathrm{R}^{2}\right.$ for full model $=.221, p$ $=.014)$.

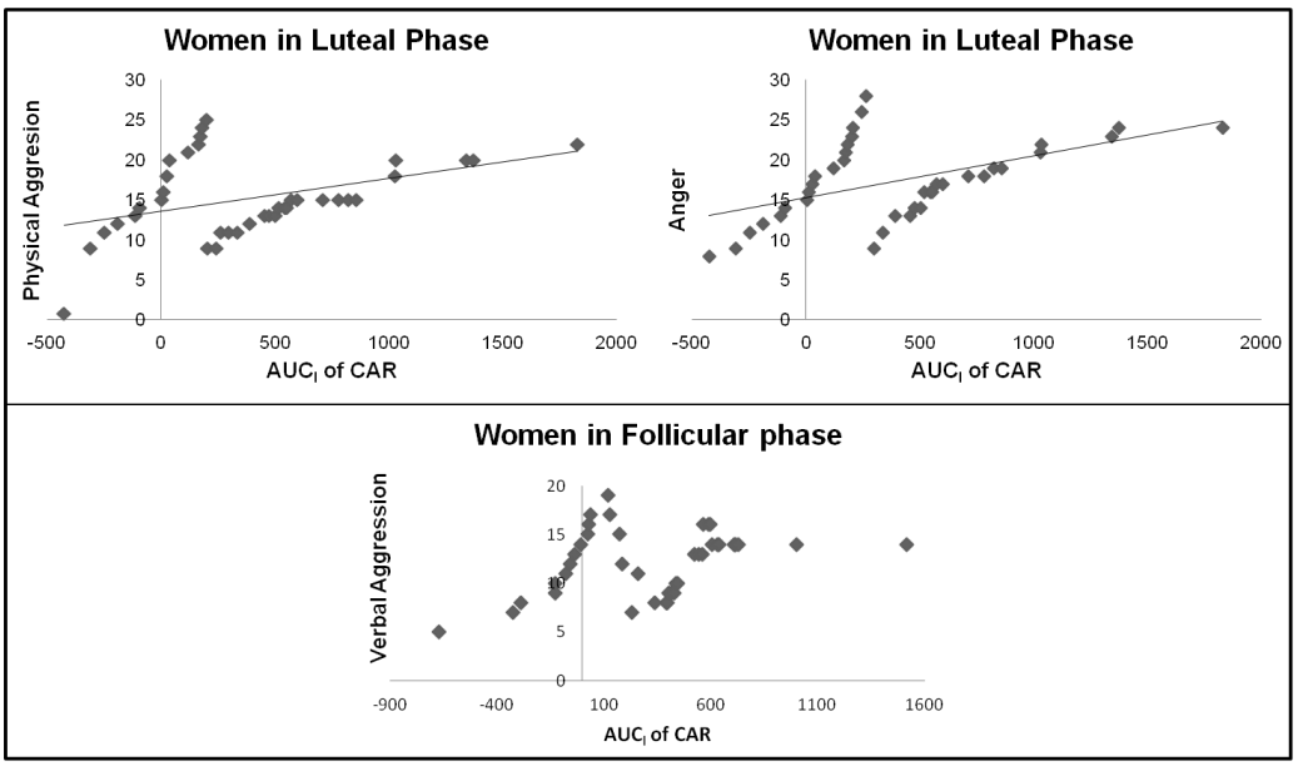

Figure 3. Relationship between AUC of CAR and anger, verbal and physical aggression for women in luteal and follicular phase, $p \leq .05$.

\section{Discussion}

In this study, compared to women in the luteal phase of the menstrual cycle, men had lower levels of $\mathrm{C}$ when recovering from the peak of the CAR, that is, at 30 and 45 minutes after awakening. In addition, general aggression and specifically verbal aggression proved to be predictors of CAR in men. In the case of women, verbal aggression predicted CAR during the follicular phase of the cycle, whereas anger and physical aggression predicted CAR during the luteal phase. These predictors were positively related to $\mathrm{C}$, with the exception of high physical aggression, which predicted a low CAR in the case of women in the luteal phase.

Many research findings have indicated that aggressive behavior may be influenced by gender, since it is commonly observed that men exhibit more conduct problems than women (Huesmann, Dubow, \& Boxer, 2009; Moffitt, Caspi, Rutter, \& Silva, 2001; Zheng \& Cleveland, 2013). Moreover, several studies have indicated that men show more physical aggression than women (Archer, 2009; Buss \& Perry, 1992; Tsorbatzoudis, Travlos, \& Rodafinos, 2013). On the other hand, women were found to have higher levels of physical aggression in the luteal than the follicular phase (Ritter, 2003). In our study, men had higher scores for physical aggression than women. Nevertheless, the differences were observed between men and women in the follicular phase.
Accordingly, further research is need to clarify the role of menstrual cycle in the aggression levels of women.

Regarding the CAR levels, the magnitude of the typical CAR has been described in relative terms with increases from 38 to $75 \%$ of awakening levels, as well as in absolute terms as an increase greater than or equal to $2.5 \mathrm{nmol} / 1$ (Edwards, et al., 2001). Our results with healthy young participants show a peak in $\mathrm{C}$ at 30 minutes and a progressive decrease to 45 and 60 minutes after awakening. These results are consistent with similar findings in previous research on CAR (Clow, Thorn, Evans, \& Hucklebridge, 2004) with percentage increases of $70.44 \%, 65.58 \%$ and $38.63 \%$ from immediately after waking until 30, 45 and 60 minutes later, respectively. Awakening time has been shown to influence the CAR (Kudielka \& Kirschbaum, 2003) and other individual variables such as sleep duration or sleep quality could affect the first C values after awakening (Fries, et al., 2009; Griefahn \& Robens, 2011; Smyth, Clow, Thorn, Hucklebridge, \& Evans, 2013). However, we controlled for all these possibilities and the consideration of the first $C$ values in our statistical analysis as a covariate gives greater ecological validity to the sample.

Previous studies did not find significant gender differences or differences between women in different phases of the menstrual cycle phase in CAR (Kudielka \& Kirschbaum, 2003, 2005). However, those and other previous studies only considered separately the effect of the gender or the menstrual cycle phase in the CAR levels (Kunz-Ebrecht, et al., 
2004; Wolfram, et al., 2011). Authors that considered gender, menstrual cycle phases and women who used oral contraceptives did not find differences between groups; nonetheless, they found that women in the luteal phase presented higher magnitude CAR than the rest of the groups (Kirschbaum, et al., 1999). Our data partially support these last results in that men presented lower levels of CAR than women in the luteal phase, but the differences between groups in the magnitude of response were not significant. On the other hand, we excluded women taking oral contraceptives from our analysis.

Few studies have investigated the role of the menstrual cycle phase on aggressive behavior. High scores of aggression have been reported in women with premenstruum dysphoria (Salamat, Ismail, \& O’Brien, 2008; Van Goozen, Frijda, Wiegant, Endert, \& Van de Poll, 1996). Moreover, a positive correlation was found between laboratory-measured aggression and plasma $T$ when women were only tested during the follicular phase (Dougherty, Bjork, Moeller, \& Swann, 1997). Estrogen values were positively correlated with 'verbal aggression' scores in the follicular phase and positively with 'resentment' in the premenstruum, while progesterone levels were negatively correlated with 'suspiciousness' and 'resentment' in the premenstrual cycle phase of the cycle (Brambilla, Speca, Pacchiarotti, \& Biondi, 2010). However, to our knowledge, no studies have clarified the relationship between aggressive behavior and CAR. Our results suggest that aggression scores are associated with increases in CAR levels - but depend on gender and menstrual cycle phase. Physical aggression was only positively associated with increases in CAR levels in the case of the women in the luteal phase. This supports the findings of a previous study that increases in CAR levels (after exogenous administration of $\mathrm{C}$ ) were positively associated with aggressive behavior (Böhnke, et al., 2010b). Nevertheless, the same group identified a negative relationship between basal CAR levels and aggressive behavior (Böhnke, et al., 2010a). Our work differs from these studies in that we have used a questionnaire on aggression to categorize this construct - while the aforementioned authors employed a laboratory task. Fur-

\section{References}

Archer, J. (2009). Does sexual selection explain human sex differences in aggression? Behavioral and Brain Sciences, 32(3-4), 249-266. doi:0.1017/S0140525X09990951

Brambilla, F., Speca, A., Pacchiarotti, I., \& Biondi, M. (2010). Hormonal background of physiological aggressiveness in psychologically healthy women. International Journal of Psychophysiology, 75(3), 291-294. doi:10.1016/j.ijpsycho.2009.12.012

Böhnke, R., Bertsch, K., Kruk, M.R., \& Naumann, E. (2010a). The relationship between basal and acute HPA axis activity and aggressive behavior in adults. Journal of Neural Transmission, 117(5), 629-637. doi:10.1007/s00702-010-0391-x

Böhnke, R., Bertsch, K., Kruk, M.R., Richter, S., \& Naumann, E. (2010b). Exogenous cortisol enhances aggressive behavior in females, but not in males. Psychoneuroendocrinology, $35(7), \quad$ 1034-44. doi:10.1016/j.psyneuen.2010.01.004 ther research is need to clarify the relationship between these variables.

The main limitation of this study is that it is crosssectional, so individual differences may mask other effects evaluated at a single moment in life. Secondly, it is important to recognize its exploratory nature. Moreover, we studied a non-clinical sample, which limits the external validity of the finding of a relationship between $\mathrm{C}$ or CAR levels and aggressive behavior in a non-violent population. Finally, our study did not consider that some women have shorter menstrual cycle phases than others.

In summary, based on all the data presented and considering that aggressive behavior is a major public health problem associated with a high annual cost in healthcare, lawsuits, and loss of productivity in some countries (MoyaAlbiol, 2010), it is necessary to continue investigating hormonal correlates of aggressive behavior to improve our understanding of this phenomenon. Specifically, in future research, it would be interesting to expand the study to include other hormonal variables that could be affected by aggressive behavior in clinical and non-clinical samples. For example, recently, the Triple Imbalance Hypothesis of reactive aggression has suggested that predisposition for social aggression is a consequence of an imbalance between $\mathrm{C}$ and testosterone ( $\mathrm{T}$ ) (Denson, Mehta, \& Ho Tan, 2013; Montoya, Terburg, Bos, \& van Honk, 2012). According to the dual-hormone hypothesis, high $\mathrm{T}$ and low $\mathrm{C}$ could predispose an individual to aggression and violence (RomeroMartínez, González-Bono, Lila, \& Moya-Albiol, 2013; Romero-Martínez, Lila, Sariñana-González, González-Bono, \& Moya-Albiol, 2013).

Acknowledgements.- The authors wish to thank John Rawlins for the revision of the English text, and Dra. Esperanza GonzálezBono and Dra. Sara de Andrés-García for their collaboration. This study was supported by the Spanish Ministry of Health, Social Services and Equality (2012/001); the Department of Trade, Science and Research of the Valencia Regional Government (GVPRE/2008/260, GVACOMP/2010/250, and PROMETEO2011/048), by the Spanish Ministry of Science and Innovation (PSI2008-04408), and by the University of Valencia (UV-INVAE11-41173).

Bouma, E.M., Riese, H., Ormel, J., Verhulst, F.C., \& Oldehinkel, A.J. (2009). Adolescents' cortisol responses to awakening and social stress; effects of gender, menstrual phase and oral contraceptives. The TRAILS study. $\begin{array}{lll}\text { Psychoneuroendocrinology, } & 34(6), & 884-93 .\end{array}$ 10.1016/j.psyneuen.2009.01.003

Brewer-Smyth, K., Burgess, A.W., \& Shults, J. (2004). Physical and sexual abuse, salivary cortisol, and neurologic correlates of violent criminal behavior in female prison inmates. Biological Psychiatry, 55(1), 21-31. doi:10.1016/S0006-3223(03)00705-4

Buss, A.H., \& Durkee, A. (1957). An inventory for assessing different kinds of hostility. Journal of Consulting Psychology, 21(4), 343-349. doi: $10.1037 /$ h0046900

Buss, A.H., \& Perry, M. (1992). The aggression questionnaire. Journal of Personality and Social Psychology, 63(3), 452-459. 
Chida, Y., \& Steptoe, A. (2009). Cortisol awakening response and psychosocial factors: a systematic review and meta-analysis. Biological psychology, 80(3), 265-278. doi:10.1016/j.biopsycho.2008.10.004

Cima, M., Smeets, T., \& Jelicic, M. (2008).Self-reported trauma, cortisol levels, and aggression in psychopathic and non-psychopathic prison inmates. Biological Psychology, 78(1), 75-86. doi: 10.1016/j.biopsycho.2007.12.01

Clow, A., Hucklebridge, F., Stalder, T., Evans, P., \& Thorn, L. (2010). The cortisol awakening response: More than a measure of HPA axis function. Neuroscience \& Biobehavioral Reviens, 35, 97-103. doi:10.1016/j.neubiorev.2009.12.011

Clow, A., Thorn, L., Evans, P., \& Hucklebridge, F. (2004). The awakening cortisol response: Methodological issues and significance. Stress: The International Journal on the Biology of Stress, 7(1), 29-37. doi: 10.1080/10253890410001667205

Dawes, M.A., Dorn, L.D., Moss, H.B., Yao, J.K., Kirisci, L., Ammerman, R.T., \& Tarter, R.E. (1999). Hormonal and behavioralhomeostasis in boys at risk for substance abuse. Drug and Alcohol Dependence, 55, 165176. doi:10.1016/S0376-8716(99)00003-4

Denson, T.F., Mehta, P.H., \& Ho Tan, D. (2013). Endogenous testosterone and cortisol jointly influence reactive aggression in women. Psychoneuroendocrinology, 38(3), 416-24. doi: 10.1016/j.psyneuen.2012.07.003

Dougherty, D.M., Bjork, J.M., Moeller, F.G., \& Swann, A.C. (1997). The Influence of Menstrual-Cycle Phase on the Relationship between Testosterone and Aggression. Physiology \& Behavior, 62(2), 431-435. doi:10.1016/S0031-9384(97)88991-3

Edwards, S., Clow, A., Evans, P., \& Hucklebridge, F. (2001). Exploration of the awakening cortisol response in relation to diurnal cortisol secretory activity. Life Sciences, 68(18), 2093-2103. doi: S0024-3205(01)00996-1

Fairchild, G., van Goozen, S.H., Stollery, S.J., Brown, J., Gardiner, J., Herbert, J., \& Goodyer, I.M. (2008). Cortisol diurnal rhythm and stress reactivity in male adolescents with early-onset or adolescence-onset conduct disorder. Biological Psychiatry, 64(7), 599-606. doi: 10.1016/j.biopsych.2008.05.022

Fries, E., Dettenborn, L., \& Kirschbaum, C. (2009). The cortisol awakening response (CAR): Facts and future directions. International Journal of Psychophysiology, 72(1), 67-73. doi:10.1016/j.ijpsycho.2008.03.014

Gómez, J.L.G., Rodríguez, J.M.A., \& Fernández, M.E.P. (2002). Adaptación psicométrica de la versión española del cuestionario de agresión. Psicothema, 14(2), 476-482.

Griefahn, B., \& Robens, S. (2011). Cortisol awakening response - Are sampling delays of 15 minutes acceptable? International Journal of Psychophysiology, 82(2), 202-205. doi: 10.1016/j.ijpsycho.2011.08.005

Grice, J. E., \& Jackson, R. V. (2004). Letter to the Editor: Two formulas for computation of the area under the curve represent measures of total hormone concentration versus time-dependent change: A Letter to the Editor in response to JC Preussner et al.(2003) Psychoneuroendocrinology 28, 916-931. Psychoneuroendocrinology, 29(4), 563-564.

Hellhammer, J., Fries, E., Schweisthal, O., Schlotz, W., Stone, A., \& Hagemann, D. (2007). Several daily measurements are necessary to reliably assess the cortisol rise after awakening: State-and trait components. Psychoneuroendocrinology, 32(1), 80-86. doi:10.1016/j.psyneuen.2006.10.005

Huesmann, L.R., Dubow, E.F., \& Boxer, P. (2009). Continuity of aggression from childhood to early adulthood as a predictor of life outcomes: implications for the adolescent-limited and life-course-persistent models. Aggressive Behavior, 35(2), 136-149. doi: 10.1002/ab.20300

Kirschbaum, C., \& Hellhammer, D.H. (1994). Salivary cortisol in psychoneuroendocrine research: recent developments and applications. Psychoneuroendocrinology, 19(4), 313-333. doi:10.1016/0306-4530(94)90013-2

Kirschbaum, C., Kudielka, B.M., Gaab, J., Schommer, N.C., \& Hellhammer, D.H. (1999). Impact of gender, menstrual cycle phase, and oral contraceptives on the activity of the hypothalamus-pituitary-adrenal axis. Psychosomatic Medicine, 61(2), 154-162.

Krug, E.G., Mercy, J.A., Dahlberg, L.L., \& Zwi, A.B. (2002). The world report on violence and health. The lancet, 360(9339), 1083-1088. doi:10.1016/S0140-6736(02)11133-0

Kudielka, B., \& Kirschbaum, C. (2003). Awakening cortisol responses are influenced by health status and awakening time but not by menstrual cycle phase. Psychoneuroendocrinology, 28(1), 35-47. doi: S03 06 4530(02)00008-2
Kudielka, B., \& Kirschbaum, C. (2005). Sex differences in HPA axis responses to stress: A review. Biological Psychology, 69(1), 113-132. doi:10.1016/j.biopsycho.2004.11.009

Kunz-Ebrecht, S.R., Kirschbaum, C., Marmot, M., \& Steptoe, A. (2004). Differences in cortisol awakening response on work days and weekends in women and men from the white hall II cohort. Psychoneuroendocrinology, 29(4), 516-528. doi:10.1016/S0306-4530(03)00072-6

McBurnett, K., Lahey, B. B., Rathouz, P. J., \& Loeber, R. (2000). Low salivary cortisol and persistent aggression in boys referred for disruptive behavior. Archives of General Psychiatry, 57(1), 38-43. doi:10.1001/archpsyc.57.1.38.

Moffitt, T.E., Caspi, A., Rutter, M., \& Silva, P.A. (2001). Sex Differences in Antisocial Behaviour: Conduct disorder, delinquency, and violence in the Dunedin Longitudinal Study. Cambridge, UK. Cambridge University Press.

Montoya, E.R., Terburg, D., Bos, P.A., \& van Honk, J. (2012). Testosterone, cortisol, and serotonin as key regulators of social aggression: A review and theoretical perspective. Motivation and Emotion, 36(1), 65-73. doi: $10.1007 / \mathrm{s} 11031-011-9264-3$

Moya-Albiol, L. (2010). Psicobiología de la violencia. Spain. Ed. Pirámide.

Platje, E., Jansen, L., Raine, A., Branje, S., Doreleijers, T., de Vries-Bouw, M., ... Vermeiren, R. (2013). Longitudinal associations in adolescence between cortisol and persistent aggressive or rule breaking behavior. Biological Psychology, 93(1), 132-137. doi:10.1016/j.biopsycho.2013.01.002

Popma, A., Doreleijers, T.A.H., Jansen, L.M.C., Van Goozen, S.H.M., Van Engeland, H., \& Vermeiren, R. (2007). The diurnal cortisol cycle in delinquent male adolescents and normal controls. Neuropsychopharmacology, 32(7), 1622-1628. doi:10.1038/sj.npp.1301289

Pruessner, J.C., Kirschbaum, C., Meinlschmid, G., \& Hellhammer, D.H. (2003). Two formulas for computation of the area under the curve represent measures of total hormone concentration versus time-dependent change. Psychoneuroendocrinology, 28(7), 916-931. doi:10.1016/S03064530(02)00108-7

Ritter, D. (2003). Effect of menstrual cycle phase on reporting levels of aggression using the Buss and Perry Aggression Questionnaire. Aggressive Behaviour, 29(6), 531-538. doi: 10.1002/ab.10054

Romero-Martínez, A., González-Bono, E., Lila., M., \& Moya-Albiol, L. (2013). Testosterone/Cortisol Ratio in Response to Acute Stress: A Possible Marker of Risk for Marital Violence. Social Neurosciences, 8(3), 240-7. doi:10.1080/17470919.2013.772072

Romero-Martínez, A., Lila, M., Conchell, R., González-Bono, E., \& MoyaAlbiol, L., (2014). Immunoglobulin A response to acute stress in intimate partner violence perpetrators: the role of anger expression-out and testosterone. Biological psychology, 96, 66-71. doi:10.1016/j.biopsycho.2013.11.009

Romero-Martínez, Á., Lila, M., Sariñana-González, P., González-Bono, E., \& Moya-Albiol, L. (2013). High testosterone levels and sensitivity to acute stress in perpetrators of domestic violence with low cognitive flexibility and impairments in their emotional decoding process: A preliminary study. Aggressive behavior, 39(5), 355-369. doi: 10.1002/ab.21490

Salamat, S., Ismail, K.M.K., \& O’ Brien, S. (2008). Premenstrual syndrome. Obstetrics, Gynaecology \& Reproductive Medicine, 18(2), 29-32. doi:10.1016/j.ogrm.2007.11.006

Smyth, N., Clow, A., Thorn, L., Hucklebridge, F., \& Evans, P. (in press). Delays of 5-15 min between awakening and the start of saliva sampling matter in assessment of the cortisol awakening response. Psychoneuroendocrinology. 10.1016/j.psyneuen.2012.12.013

Tsorbatzoudis, H., Travlos, A.K., \& Rodafinos, A. (2013). Gender and Age Differences in Self-Reported Aggression of High School Students. Journal of Interpersonal Violence, 28(8), 1709-1725. doi: $10.1177 / 0886260512468323$

Van den Bergh, B., Van Calster, B., Pinna Puissant, S., \& Van Huffel, S. (2008). Self-reported symptoms of depressed mood, trait anxiety and aggressive behavior in post-pubertal adolescents: Associations with diurnal cortisol profiles. Hormones and Behavior, 54(2), 253-257. doi:10.1016/j.yhbeh.2008.03.015

Van Bokhoven, I., Van Goozen, S., Van Engeland, H., Schaal, B., Arseneault, L., Seguin, J., ... Tremblay, R.E. (2005). Salivary cortisol and aggression in a population-based longitudinal study of adolescent 
males. Journal of Neural Transmission, 112(8), 1083-1096. doi: $10.1007 / \mathrm{s} 00702-004-0253-5$

Van Goozen, S.H., Frijda, N.H., Wiegant, V.M., Endert, E., \& Van de Poll, N.E. (1996). The premenstrual phase and reactions to aversive events: a study of hormonal influences on emotionality. Psychoneuroendocrinology, 21(5):479-497. doi:10.1016/0306-4530(95)00022-4

Vermeersch, H., T'Sioen, G., Kaufman, J.M., Vincke, J. (2008). Estradiol, testosterone, differential association and aggressive and non-aggressive risk-taking in adolescent girls. Psychoneuroendocrinology, 33(7), 897-908. doi: 10.1016/i.psyneuen.2008.03.016.

Wolfram, M., Bellingrath, S., \& Kudielka, B.M. (2011). The cortisol awakening response (CAR) across the female menstrual cycle. Psychoneuroendocrinology, 36(6), 905-912. doi:10.1016/j.psyneuen.2010.12.006
Wüst, S., Federenko, I., Hellhammer, D.H., \& Kirschbaum, C. (2000). Genetic factors, perceived chronic stress, and the free cortisol response to awakening. Psychoneuroendocrinology, 25(7), 707-720. doi: S03 06 4530(00)00021-4

Zheng, Y., \& Cleveland, H.H. (2013). Identifying gender-specific developmental trajectories of nonviolent and violent delinquency from adolescence to young adulthood. Journal of Adolescence, 36(2), 371-381. doi: 10.1016/j.adolescence.2012.12.007

(Article received: 25-06-2013; revised: 11-10-2014; accepted: 11-10-2014) 